\section{Postoperative coma in a patient with complete basilar syndrome after anterior cervical discectomy}

To the Editor:

We applaud Tsai et al., ${ }^{1}$ for drawing attention to the rare but devastating postoperative complication of basilar stroke. We would like to point out that proximate surgery in the neck may be coincidental rather than causative. In fact, we have reported a similar case that occurred after nephrectomy in which the cervical spine was not manipulated at all. ${ }^{2}$ Furthermore, we would like to suggest that consideration be given to early neuroradiologic or thrombolytic intervention, which may offer some chance to improve outcomes when basilar stroke is diagnosed early. ${ }^{3}$

David P. Martin MD PhD

Christopher J. Jankowski MD

Mark T. Keegan MB MRCPI

Laurence C. Torsher MD FRCPC

Mayo Clinic College of Medicine, Rochester, USA

E-mail: martin.david@mayo.edu

Accepted for publication March 20, 2006.

\section{References}

1 Tsai YF, Doufas AG, Huang CS, Liou FC, Lin CM. Postoperative coma in a patient with complete basilar syndrome after anterior cervical discectomy. Can J Anesth 2006; 53: 202-7.

2 Martin DP, Jankowski CJ, Keegan MT, Torsher LC. Postoperative confusion and basilar artery stroke. Neurocrit Care 2006; 4: 148-51.

3 Qureshi AI, Siddiqui AM, Suri MF, et al. Aggressive mechanical clot disruption and low-dose intra-arterial third-generation thrombolytic agent for ischemic stroke: a prospective study. Neurosurgery 2002; 51 : 1319-27.

\section{Indirect vertebral artery injury during cervical spine surgery}

To the Editor:

Tsai et al. present an interesting case of massive cerebral infarction and subsequent death after anterior cervical discectomy and fusion. ${ }^{1}$ The authors state that the cervical hyperextension may have led to cerebral ischemia and subsequent cerebral infarction. ${ }^{1}$ We offer several comments relevant to their case. First, it appears the patient had two primary risk factors, diabetes and hypertension, for vascular disease. We published a very similar case on a 56-yr-old male with hypertension and diabetes who underwent a C6 anterior cervical corpectomy for myelopathy. ${ }^{2}$ Our patient tolerated the procedure well, with minimal blood loss, normal intraoperative neurophysiological monitoring, and a normal intraoperative 'wake-up' test. Postoperatively, the patient was neurologically 'sluggish'. An emergent computerized tomography (CT) scan of the brain and spine demonstrated posterior circulation infarcts and a normal spine. A vertebral artery dissection was demonstrated on angiography. The patient continued to have embolic infarcts requiring a suboccipital craniectomy for evacuation of edematous and infarcted cerebellum with subsequent sacrifice of the vertebral artery via aneurysm clipping. The patient died two weeks postoperatively. ${ }^{2}$ We investigated at length the possible etiologies for the vertebral dissection and concluded it was likely cervical traction. We also routinely utilize cervical hyperextension in our anterior cervical spine cases, but believe that traction on an atherosclerotic vessel led to the dissection. Vertebral artery dissection has been reported to occur spontaneously, with spinal trauma, after chiropractic treatment, and associated with suicide via hanging, all of which could result in either direct or indirect arterial injury. ${ }^{3-5}$ There are numerous reports of cerebrovascular insults secondary to vertebral artery dissection, which are most often due to thromboemboli in the posterior circulation. ${ }^{5}$ Tsai et al. denied any direct trauma, however, a CT scan of the cervical spine might have demonstrated a breach of the transverse foramen leading to a vertebral dissection. Another potential mechanism of vertebral artery injury that was not discussed, was the possibility of vibrations from a high-speed drill, if utilized in the surgery, leading to a vertebral dissection.

To support Tsai et al. on the hypothesis of a hyperextension injury, there are reports of chiropractic manipulation causing vertebral injury due to extension of the neck with rotation causing intraforaminal contortion of the vessel leading to dissection. ${ }^{6}$ In addition, are the cases of "salon syndrome" where the neck is hyperextended for hairwashing and the person subsequently suffers neurological sequelae. ${ }^{7}$ Lastly, magnetic resonance angiography has demonstrated that certain patients have significantly decreased vertebro-basilar flow with cervical hyperextension, and are thus at an increased risk for ischemia with hyperextension. ${ }^{8}$

In closing, we support Tsai et al. on their recommendations for limiting cervical hyperextension in patients at risk for vascular disease, i.e., diabetes and 
hypertension. We also suggest no cervical traction, and maintaining the head and neck in a neutral position throughout the case to ensure adequate circulation; this includes both anterior and posterior cervical spine surgery. Furthermore, cerebral vascular insult should be mentioned preoperatively as a risk of surgery, for all patients with vascular disease or comorbidities at risk for vascular disease.

Rob D. Dickerman DO PhD

Ashley S. Reynolds RN

Jeff Cattorini MD

Plano Presbyterian and Baylor Garland Hospital, Plano, USA

E-mail: drrdd@yahoo.com

Accepted for publication March 20, 2006.

\section{References}

1 Tsai YF, Doufas AG, Huang CS, Liou FC, Lin CM. Postoperative coma in a patient with complete basilar syndrome after anterior cervical discectomy. Can J Anesth 2006, 53: 202-7.

2 Dickerman RD, Zigler JE. Atraumatic vertebral artery dissection and death after cervical corpectomy: a traction injury? Spine 2005, 30: E658-61.

3 Daentzer D, Deinsberger W, Boker DK. Vertebral artery complications in anterior approaches to the cervical spine: report of two cases and review of the literature. Surg Neurol 2003; 59: 300-9.

4 Iwase $H$, Kobayashi M, Kurata A, Inoue S. Clinically unidentified dissection of vertebral artery as a cause of cerebellar infarction. Stroke 2001; 32: 1422-44.

5 Sagoh M, Hirose $\Upsilon$, Murakami M, Akaji K, Mayanagi $K$. Cerebellar infarction with hydrocephalus caused by spontaneous extracranial vertebral artery dissection-case report. Neurol Med Chir (Tokyo) 1997; 37: 538-41.

6 Parenti G, Orlandi G, Bianchi M, Renna M, Martini $A$, Murri L. Vertebral and carotid artery dissection following chiropractic cervical manipulation. Neurosurg Rev 1999, 22: 127-9.

7 Endo K, Ichimaru K, Shimura H, Imakiire A. Cervical vertigo after hair shampoo treatment at a hairdressing salon: a case report. Spine 2000, 25: 632-4.

8 Weintraub MI, Khoury A. Critical neck position as an independent risk factor for posterior circulation stroke. A magnetic resonance angiographic analysis. J Neuroimaging 1995, 5: 16-22.

\section{Anesthesia for Cesarean delivery in a parturient with rigid spine syndrome}

\section{To the Editor:}

Rigid spine syndrome is a rare myopathic ailment characterized by axial and proximal muscle weakness. Muscle contraction in these patients causes limitation of neck and trunk flexion, scoliosis, and mild joint deformity. First described by Dubowitz in $1965,{ }^{1}$ the illness begins at an early age with a delay in motor development, marked limitation of flexion of the cervical and dorso-lumbar spine, scoliosis, restrictive ventilatory dysfunction, respiratory muscle weakness, and cardiac abnormalities. ${ }^{2,3}$ Anesthetic implications include a potentially difficult airway, cardiovascular problems, malignant hyperthermia susceptibility, altered response to depolarizing and non-depolarizing neuromuscular blocking agents. ${ }^{4,5}$ There are no previous reports describing anesthetic care for Cesarean delivery for this rare condition.

A 21 -yr-old primigravid patient (weight $41 \mathrm{~kg}$, height $151 \mathrm{~cm}$ ) was scheduled for elective Cesarean delivery at 34 weeks' gestation as a result of worsening respiratory symptoms. She had marked scoliosis, a restrictive ventilatory defect, and nocturnal alveolar hypoventilation requiring regular nocturnal nasal continuous positive airway pressure (CPAP) ventilation for three years prior to the current admission. Her chest $x$-ray revealed marked thoracic kyphoscoliosis and loss of lung volume. Arterial oxygen saturation $\left(\mathrm{SaO}_{2}\right)$ on room air was $94 \%$, and spirometry revealed that the forced expiratory volume in one second and forced vital capacity were $38 \%$ and $37 \%$ of predicted, respectively. The electrocadiogram and echocardiogram were normal. Airway assessment revealed a Mallampati class 2 view. The patient received a 250 $\mathrm{mL}$ bolus of lactated Ringer's solution, followed by a slow continuous $i v$ infusion. An arterial line was inserted under local anesthesia, and a combined spinal and epidural (CSE) was established without difficulty at the L4/5 level with the patient sitting. Intrathecal $0.5 \%$ bupivacaine $(7.5 \mathrm{mg})$ injected with $250 \mu \mathrm{g}$ diamorphine achieved a bilateral sensory block to ice to T7. Epidural top-up doses of $0.25 \%$ bupivacaine $(8$ $\mathrm{mL}$ in total) extended the block height to $\mathrm{T} 4$ over a period of $30 \mathrm{~min}$ with good hemodynamic stability. The patient did not experience any discomfort throughout the surgery, and required only two phenylephrine boluses of $50 \mu \mathrm{g}$ iv each, to maintain mean arterial pressure within $\pm 10 \%$ of preinduction values. Supplemental oxygen with a Hudson mask maintained $\mathrm{SaO}_{2}$ over $95 \%$. A live healthy male baby was deliv- 